\title{
VELOCITIES OF P AT SHORT DISTANCES*
}

\author{
By C. F. RICHTER
}

\begin{abstract}
Reconding of $P$ and $S$ at six or more stations to epicentral distances not over $160 \mathrm{~km}$. makes it possible to calculate the velocities, assuming only that they are constant. Origin times, epicenters, and depths are found independently of velocity.

Installation of new temporary stations has supplied appropriate data in southern California. For 6 of 8 well-recorded shocks the calculated velocity of $P$ is near $6.4 \mathrm{~km} / \mathrm{sec}$.

Consistent finding of $6 \mathrm{~km} / \mathrm{sec}$. and over for the velocity of the first longitudinal wave from quarry blasts, in southern California as elsewhere, indicates revision of the assumed velocity distribution in the upper levels of the continental crust. It calls for reinterpretation of the velocity near $5.6 \mathrm{~km} / \mathrm{sec}$. originally determined by Mohorovičic and since found from the data of earthquakes recorded at short distances in every area investigated. These points are being discussed by Gutenberg. ${ }^{1}$
\end{abstract}

TABLE 1

Stations of the Southern California Network

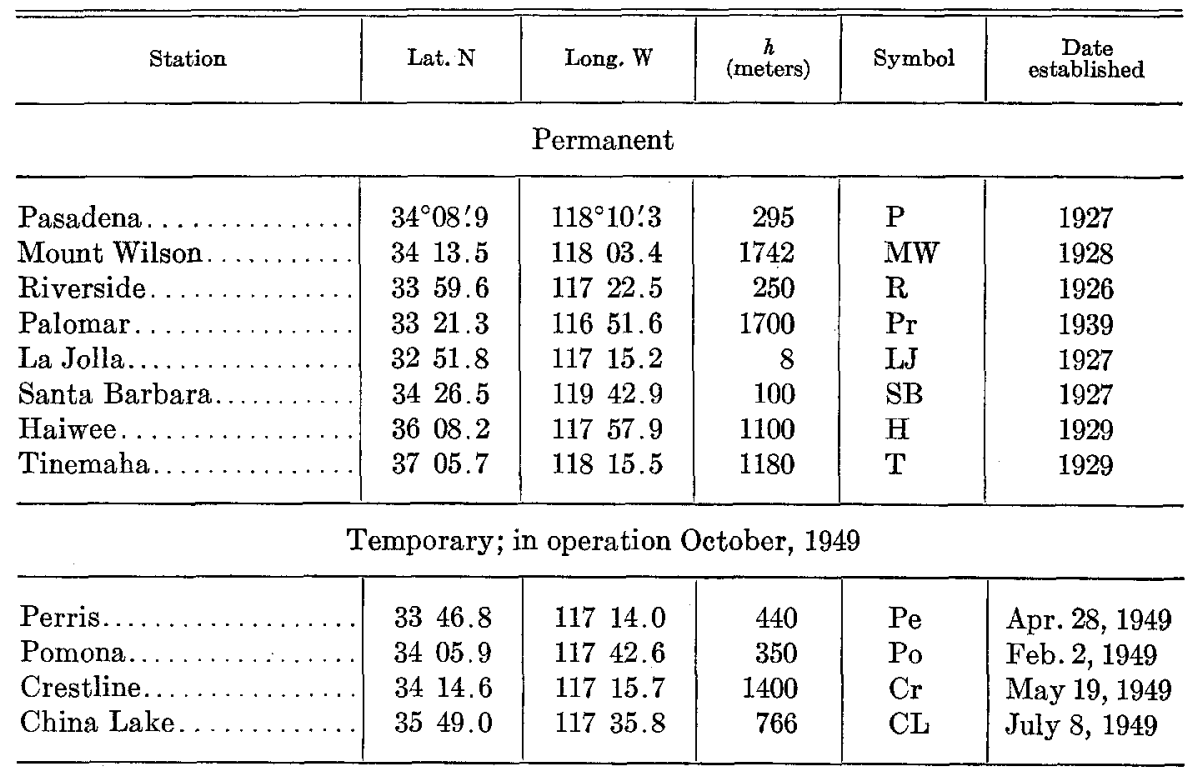

* Manuscript received for publication November 21, 1949.

i B. Gutenberg, "The Crustal Layers of the Continents," Bull. Geol. Soc. Am. (in press). 


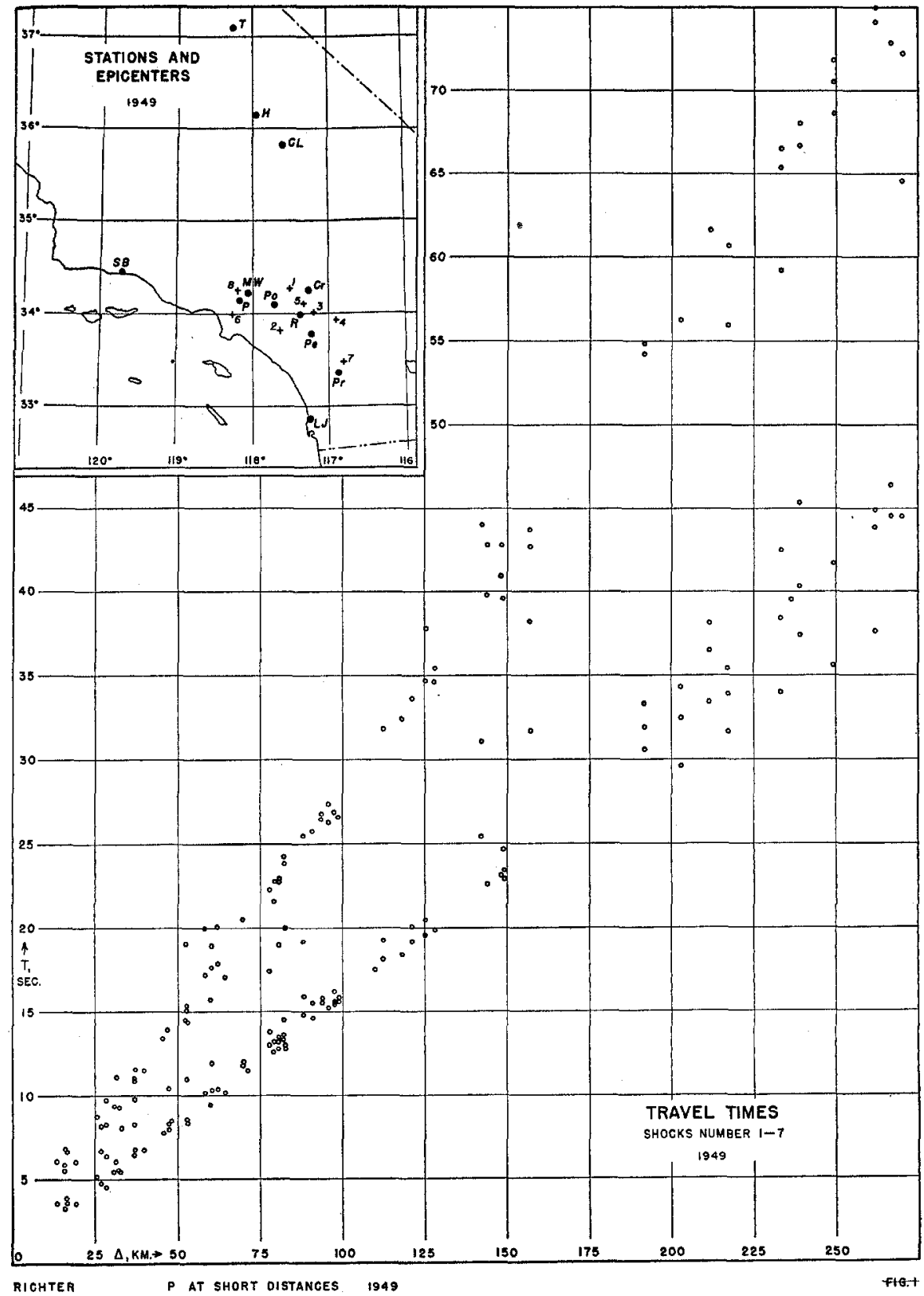

Fig. 1. Map showing epicenters and stations. Plot showing observed travel times for shocks 1-7. 
With good timing for the first longitudinal and transverse waves at six or more stations within $160 \mathrm{~km}$. of the epicenter, it is possible to calculate the velocities directly. In southern California this has been facilitated by the installation of new temporary stations to supplement those permanently established there. Coördinates and data for the entire group are given in table 1; locations are mapped in figure 1.

For the new stations we are indebted to the coöperation of officials and personnel of the Perris Grammar School, Pomona College, and Club San Moritz (near Crestline). Mr. F. E. Lehner deserves much credit for construction and installation of the recording units. These, like the permanent stations, have short-period vertical-component Benioff seismometers, drum speed of 60 $\mathrm{mm} / \mathrm{min}$, and automatically recorded radio time signals. Timing errors are not likely to exceed two-tenths of a second.

With an exception to be noted in its proper place, the velocity of longitudinal waves will be assumed to be constant, so that propagation is rectilinear. Since the velocity in question probably varies significantly with depth between the surface and the usual level at which earthquakes originate, the method can only yield a mean or average velocity. This mean is never significantly less than $6 \mathrm{~km} / \mathrm{sec}$.; it follows that the true velocity at some level must be at least as great, and probably in part exceeds this value.

Table 2 presents readings for 8 shocks, which are nearly all those clearly recorded at six or more stations of this group in a favorable range of distances, to the end of October, 1949. Times are given in seconds and tenths after the origin times, which are shown in table 3 together with epicenters, depths, and velocities.

Determination of the origin time is independent of the hypothesis of rectilinear propagation. For several of these shocks, the time interval $\mathrm{S}-\mathrm{P}$ was plotted against the arrival time of $\mathrm{P}$. The plotted points fell nearly on straight lines, which had sensibly the same slope for all the shocks. The intercept of such a line on the ordinate of zero $\mathrm{S}-\mathrm{P}$ gives the origin time. This should be valid even if there is a change of velocity along the path, provided that the ratio of the velocities of longitudinal and transverse waves remains unaltered (which is equivalent to requiring that Poisson's ratio is constant).

For most of the shocks the origin time was estimated by multiplying the $\mathrm{S}-\mathrm{P}$ time interval at each station by 1.4 to give the travel time of $\mathrm{P}$, subtracting this result from the arrival time of $P$, and taking the mean of the more consistent values thus found.

The method used to determine the velocity is essentially that of Inglada. If $x, y, z$ are Cartesian coördinates of the hypocenter, $x_{1}, y_{1}, z_{1}$ those of a station, $t_{1}$ the travel time of $\mathrm{P}$ to the station, and $v$ the velocity, then

$$
v^{2} t_{1}^{2}=\left(x-x_{1}\right)^{2}+\left(y-y_{1}\right)^{2}+\left(z-z_{1}\right)^{2} .
$$


TABLE 2

Observed Times

\begin{tabular}{|c|c|c|c|c|c|c|c|c|}
\hline \multirow{8}{*}{$\begin{array}{c}\text { Shock no. } \\
1\end{array}$} & \multirow{3}{*}{$\frac{\text { Station }^{a}}{\mathrm{Po}_{\mathrm{f}}}$} & \multirow{3}{*}{$\frac{\Delta \mathrm{km} .}{28.5}$} & \multicolumn{6}{|c|}{ Travel times } \\
\hline & & & \multicolumn{3}{|c|}{$\mathrm{P}$ group } & \multicolumn{3}{|c|}{$\mathrm{S}$ group } \\
\hline & & & 4.6 & 6.4 & & 8.3 & 9.8 & \\
\hline & $\mathrm{R}$ & 33.1 & 5.5 & & & 9.1 & & \\
\hline & $\mathrm{MW}$ & 52.8 & 8.5 & & & 14.5 & & \\
\hline & $\mathrm{Pe}$ & 60.0 & 9.5 & & & 15.7 & & \\
\hline & $P$ & 64.6 & 10.2 & & & 17.1 & & \\
\hline & $\operatorname{Pr}$ & 118.2 & 18.4 & & & 32.4 & & \\
\hline \multirow[t]{7}{*}{2} & $\mathbf{R}$ & 30.8 & 5.5 & & & 9.4 & & \\
\hline & Po & 31.6 & $6.1=$ & & & $11.1=$ & & \\
\hline & $\mathrm{Pe}$ & $37 . \theta$ & 6.5 & & & 10.9 & & \\
\hline & $\mathrm{Cr}$ & 58.6 & 10.2 & & & 17.2 & 20.0 & \\
\hline & MW & 60.2 & 10.4 & 12.0 & & 17.7 & 19.0 & \\
\hline & $\mathrm{P}$ & 62.2 & 10.4 & & & 17.9 & 20.1 & \\
\hline & $\operatorname{Pr}$ & 88.3 & 14.8 & 15.9 & 19.2 & 25.5 & & \\
\hline \multirow[t]{12}{*}{3} & $\mathbf{R}$ & 16.5 & 3.6 & & & 6.7 & & \\
\hline & $\mathrm{Pe}$ & 26.8 & 4.8 & 6.7 & & 8.2 & & \\
\hline & $\mathrm{Cr}$ & 25.4 & 5.2 & & & 8.8 & & \\
\hline & Po & 48.0 & 8.5 & & & & & \\
\hline & $\operatorname{Pr}$ & 80.8 & 13.2 & 13.5 & 19.0 & 22.8 & & \\
\hline & MW & 82.3 & 13.3 & 13.6 & 14.5 & 23.9 & 24.2 & \\
\hline & $\mathrm{P}$ & 90.9 & 14.6 & 15.5 & & 25.8 & & \\
\hline & $\mathrm{LJ}$ & 128.3 & 19.9 & & & 34.6 & 35.4 & \\
\hline & CL & 202.7 & 29.6 & 32.5 & 34.3 & 56.2 & & \\
\hline & SB & 236.5 & 39.5 & & & & & \\
\hline & $\mathrm{H}$ & 249.3 & 35.6 & 41.7 & & 68.6 & 70.5 & 71.8 \\
\hline & $\mathrm{T}$ & 358.7 & 49.6 & 56.2 & 59.4 & 98.8 & 99.5 & \\
\hline \multirow[t]{12}{*}{4} & $\mathrm{Pe}$ & 37.5 & 6.8 & & & 11.6 & & \\
\hline & $\mathrm{R}$ & 45.7 & 7.8 & & & 13.4 & & \\
\hline & $\mathrm{Cr}$ & 47.2 & 8.3 & 10.4 & & 13.9 & & \\
\hline & $\operatorname{Pr}$ & 66.6 & 11.5 & & & & & \\
\hline & $\mathrm{Po}$ & 78.0 & 13.0 & 13.8 & 17.4 & 22.3 & & \\
\hline & MW & 112.5 & 18.1 & 19.2 & & 31.8 & & \\
\hline & $\mathrm{P}$ & 121.3 & 19.2 & 20.1 & & 33.6 & & \\
\hline & LJ & 125.3 & 19.6 & 20.5 & & 34.7 & 37.8 & \\
\hline & CL & 217.2 & 31.6 & 33.9 & 35.4 & 55.9 & 60.6 & \\
\hline & $\mathrm{H}$ & 261.9 & 37.6 & 43.9 & 44.9 & 74.1 & 75.0 & 76.0 \\
\hline & $\mathrm{SB}$ & 266.7 & 44.5 & 46.4 & & 72.8 & 77.3 & \\
\hline & $\mathrm{T}$ & 372.1 & 50.6 & 59.9 & & 102.0 & 103.2 & \\
\hline
\end{tabular}

a For explanation of abbreviations of station names see table 1 . 
TABLE 2-Continued

\begin{tabular}{|c|c|c|c|c|c|c|c|c|}
\hline \multirow{2}{*}{ Shock no. } & \multirow{2}{*}{ Station } & \multirow{2}{*}{$\Delta \mathrm{km}$} & \multicolumn{6}{|c|}{ Travel times } \\
\hline & & & & $P$ group & & & $\mathrm{S}$ group & \\
\hline \multirow[t]{10}{*}{5} & $\mathrm{R}$ & 13.6 & 3.6 & & & 6.1 & & \\
\hline & $\mathrm{Cr}$ & 16.1 & 3.9 & & & 6.8 & & \\
\hline & Po & 36.8 & 6.8 & 8.3 & 9.8 & 11.0 & & \\
\hline & $\mathrm{Pe}$ & 39.9 & 6.8 & & & 11.5 & & \\
\hline & MW & 70.1 & 11.8 & 12.0 & & 20.5 & & \\
\hline & $\mathrm{P}$ & 79.6 & 13.2 & & & 22.8 & & \\
\hline & $\mathrm{Pr}$ & 93.7 & 15.5 & 15.8 & & 26.5 & 26.8 & \\
\hline & CL & 191.7 & 30.6 & 31.9 & 33.3 & 54.2 & 54.8 & \\
\hline & $\mathrm{H}$ & 233.2 & 39.0 & 43.4 & 47.5 & 59.2 & 65.3 & 66.5 \\
\hline & $\mathrm{T}$ & 342.7 & 56.7 & 70.2 & & 97.1 & 99.6 & \\
\hline \multirow[t]{12}{*}{6} & $\mathrm{P}$ & 19.3 & 3.6 & & & 6.1 & & \\
\hline & MW & 32.3 & 5.6 & & & 9.3 & & \\
\hline & Po & 52.8 & 8.6 & 11.0 & & 15.1 & 19.1 & \\
\hline & $\mathrm{R}$ & 82.7 & 12.8 & 13.0 & & 22.0 & & \\
\hline & $\mathrm{Cr}$ & 97.6 & 15.4 & 15.6 & 16.2 & 26.9 & & \\
\hline & $\mathrm{Pe}$ & 98.8 & 15.6 & 15.8 & & 26.6 & & \\
\hline & SB & 142.2 & 25.4 & 31.1 & & 44.0 & & \\
\hline & Pr & 149.1 & 22.9 & 23.4 & 24.7 & 39.6 & & \\
\hline & LJ & 157.1 & 31.7 & 38.2 & & 42.7 & 43.7 & \\
\hline & CL & 211.4 & 33.4 & 36.5 & 38.1 & 61.2 & & \\
\hline & $\mathrm{H}$ & 239.3 & 37.4 & 40.3 & 45.3 & 66.6 & 68.0 & \\
\hline & $\mathrm{T}$ & 344.0 & 50.5 & 58.9 . & 60.4 & & & \\
\hline \multirow[t]{10}{*}{7} & $\operatorname{Pr}$ & 15.7 & 3.3 & & & 5.5 & 5.9 & \\
\hline & $\mathrm{Pe}$ & 53.0 & 8.4 & & & 14.4 & 15.4 & \\
\hline & $\mathrm{R}$ & 79.2 & 12.6 & & & 21.6 & & \\
\hline & $\mathrm{LJ}$ & 80.7 & 12.8 & & & 22.9 & & \\
\hline & $\mathrm{Cr}$ & 95.8 & 15.2 & & & 26.3 & 27.4 & \\
\hline & Po & 109.9 & 17.5 & & & & & \\
\hline & MW & 144.0 & 22.6 & & & 39.8 & 42.8 & \\
\hline & $\mathrm{P}$ & 148.3 & 23.1 & & & 40.9 & 42.8 & \\
\hline & CL & 270.2 & 44.5 & & & 64.5 & 72.2 & 76.7 \\
\hline & $\mathrm{H}$ & 314.4 & & & & 112.3 & & \\
\hline \multirow[t]{7}{*}{$8^{b}$} & MW & 11.7 & 1.5 & & & 2.3 & & \\
\hline & $\mathrm{P}$ & 11.4 & 2.0 & & & 3.4 & & \\
\hline & Po & 47.4 & 7.0 & & & & & \\
\hline & $\mathbf{R}$ & 79.6 & 12.0 & & & 20.6 & & \\
\hline & $\mathrm{Cr}$ & 84.7 & 13.1 & & & 23.1 & & \\
\hline & $\mathrm{Pe}$ & 101.9 & 15.7 & & & 27.7 & & \\
\hline & $\operatorname{Pr}$ & 158.1 & 24.1 & & & $40.9 ?$ & 42.5 & 43.2 \\
\hline
\end{tabular}

b Readings for No. 8 are not plotted in the figure. 
Writing the similar equation for a second station, subtracting and transposing,

$$
2\left(x_{1}-x_{2}\right) x+2\left(y_{1}-y_{2}\right) y+2\left(z_{1}-z_{2}\right) z+v^{2}\left(t_{1}^{2}-t_{2}^{2}\right)=r_{1}^{2}-r_{2}^{2}
$$

with the usual meaning of $r_{1}$ and $r_{2}$. The coördinate $z$ can be neglected if the effect of difference in level between the stations can be eliminated. Mount Wilson, Palomar, and Crestline are at appreciably greater elevation than the neighboring stations. This has been compensated by arbitrarily subtracting

TABLE 3

Locatrons, Origin Times, Magnitudes and Velocities

\begin{tabular}{|c|c|c|c|c|c|c|c|}
\hline \multirow{2}{*}{$\begin{array}{c}\text { Shoek } \\
\text { no. }\end{array}$} & \multirow{2}{*}{$\begin{array}{l}\text { Date } \\
1949\end{array}$} & \multirow{2}{*}{$\begin{array}{c}\text { Origin } \\
\text { time }\end{array}$} & \multicolumn{2}{|c|}{ Epicenter } & \multirow{2}{*}{$\mathrm{Km}$. } & \multirow{2}{*}{ Mag. } & \multirow{2}{*}{$\begin{array}{c}\text { P velocity } \\
\text { (caleu- } \\
\text { lated) }\end{array}$} \\
\hline & & & Lat. N & Long. W & & & \\
\hline 1 & May 6 & $17: 14: 13.0$ & $34^{\circ} 16: 6$ & $117^{\circ} 29^{\prime} .4$ & 13 & 2.6 & 6.49 \\
\hline 2 & July 18 & $12: 14: 28.9$ & $33 \quad 48.9$ & 11737.8 & 13 & 2.9 & 6.07 \\
\hline 3 & Aug. 16. & $21: 14: 20.2$ & 3401.2 & 11712.0 & 17 & 3.4 & 6.46 \\
\hline 4 & Aug. 19. & $02: 57: 50.6$ & 3357.0 & 11652.9 & 24 & 3.8 & 6.50 \\
\hline 5 & Aug. 31 . & $02: 58: 41.6$ & $\begin{array}{lll}34 & 06.3\end{array}$ & 11718.7 & 18 & 2.9 & 6.22 \\
\hline 6 & Sept. 18. . & $21: 08: 13.0$ & 3359.7 & 11816.2 & 14 & 3.1 & 6.43 \\
\hline 7 & Oct. $16 \ldots$ & $00: 01: 47.1$ & 3328.9 & 11647.3 & 16 & 2.8 & 6.43 \\
\hline 8 & Oct. $21 \ldots$ & $00: 18: 33.3$ & 3415.0 & $118 \quad 10.8$ & $0 ?$ & 2.3 & 6.56 \\
\hline
\end{tabular}

one-tenth of a second from the times of arrival at the three elevated stations, taking the reduced time to be that of arrival at about sea level below them. We then may put $z_{1}=z_{2}$, and the last equation is of the form

$$
a x+b y+c v^{2}=q
$$

Since $q$ is a known constant, a set of such equations is appropriate for solution by the method of least squares in the Gaussian form.

For five stations, equations are formed involving $x_{1}-x_{2}, x_{2}-x_{3}, x_{3}-x_{4}$, $x_{4}-x_{5}$, and $x_{5}-x_{1}$. The last equation is not independent; it is included to complete the cycle, in order to give all the stations equal weight.

Coördinates $x, y$ have been calculated for the stations by using the tables published by the author. ${ }^{2}$ Slight differences, of no practical consequence, result from shifting the origin of $x, y$. Table 4 gives coördinates $x, y$ and the corresponding $r^{2}$ for the stations of table 1 , with the origin at $34^{\circ} 00^{\prime} \mathrm{N}, 117^{\circ} 30^{\prime} \mathrm{W}$.

Standard errors for $v^{2}$ were calculated in a few instances, but appeared deceptively small. A better idea of the closeness with which the observations are

2 "Calculation of Small Distances," Bull. Seism. Soc. Am., 33: 243-250 (1943). 
represented may be obtained by comparing observed with calculated times for a particular shock. The depth $h$ must first be determined. The solution for epicenter and velocities is independent of depth; but once $x, y$, and $v^{2}$ are determined, $h$ may be calculated individually from the data of each station. $\Delta$ is found from $\Delta^{2}=\left(x-x_{1}\right)^{2}+\left(y-y_{1}\right)^{2}$; then computing $D^{2}=v^{2} t^{2}$ we find $h^{2}=D^{2}-\Delta^{2}$. The values of $h$ from different stations usually diverge considerably. For shock no. 4 they ranged from 22 to $32 \mathrm{~km}$. The values from the

TABLE 4

Coördinates with Origrn at $34^{\circ} 00^{\prime} \mathrm{N}$., $117^{\circ} 30^{\prime} \mathrm{W}$

\begin{tabular}{|c|c|c|c|c|}
\hline Station & $x$ & $y$ & $r^{2}$ & $r$ \\
\hline Pasadena..... & -62.00 & +16.45 & 4114.6025 & 64.15 \\
\hline Mount Wilson.. & -51.36 & +24.96 & 3260.8512 & 57.10 \\
\hline Riverside.... . & +11.55 & -00.74 & 133.9501 & 11.57 \\
\hline Palomar.... & +59.51 & -72.10 & 8739.8501 & 93.49 \\
\hline La Jolla. . & +22.94 & -126.07 & 16419.8885 & 128.14 \\
\hline Santa Barbara. & -204.11 & +48.99 & 44060.9122 & 209.91 \\
\hline Haiwee........ & -42.42 & +237.04 & 57987.4180 & 240.81 \\
\hline Tinemaha. & -68.40 & +343.38 & 122588.3844 & 350.13 \\
\hline Perris...... & +24.67 & -24.40 & 1203.9689 & 34.70 \\
\hline Pomona..... & -19.44 & +10.87 & 496.0705 & 22.27 \\
\hline Crestline... & +21.99 & +26.99 & 1212.0202 & 34.81 \\
\hline China Lake.. & -8.83 & +201.44 & 40656.0245 & 201.63 \\
\hline
\end{tabular}

data of the nearer stations of course deserve greater weight. For the shock named, $h$ was assumed as $24 \mathrm{~km}$. (which is exceptionally large), and times were accordingly calculated with the velocity $6.5 \mathrm{~km} / \mathrm{sec}$. as found. The results may be summarized as follows:

\begin{tabular}{|c|c|c|c|c|c|c|c|c|}
\hline Station ${ }^{3} \ldots$ & $\mathrm{Pe}$ & $\mathrm{R}$ & $\mathrm{Cr}$ & $\operatorname{Pr}$ & Po & MW & $\mathrm{P}$ & $\mathrm{LJ}$ \\
\hline$h$ (calc). & 23.4 & 22.0 & 24.8 & 32.5 & 32.4 & 32.1 & 29.1 & \\
\hline$t$ calc $(h=24)$. & 6.9 & 7.9 & 8.1 & 10.9 & 12.6 & 17.7 & 19.0 & \\
\hline tobs........... & 6.8 & 7.8 & 8.2 & 11.4 & 13.0 & 18.0 & 19.2 & \\
\hline
\end{tabular}

This example is typical; the solution normally represents the observed times within half a second or less.

The solutions given in table 3 are worked out using the times of first motion, except where that is definitely believed to be $P_{n}$. Originally, solutions were made which at the larger distances used the later short-period phase considered to be $\bar{P}$. These of course yielded lower velocities: for shocks nos. $2,3,5$, and 6 , velocities of $6.07,5.88,6.10$, and $5.83 \mathrm{~km} / \mathrm{sec}$. were found in this way. Approximately the same velocities were found if only stations less than $75 \mathrm{~km}$. distant

\footnotetext{
${ }^{3}$ For explanation of abbreviations of station names see table 1 .
} 
were used. In general, the velocity found is determined chiefly by the time of arrival at the more distant stations used. These were not included beyond $160 \mathrm{~km}$., so that Santa Barbara, China Lake, Haiwee and Tinemaha contribute to table 1 and figure 1 only.

The decision to use the first motions depended on Gutenberg's finding ${ }^{4}$ that these observations and those from quarry blasts could be reconciled much more readily by assuming that the first motion is continuous throughout, so that the sharp first arrival at the shortest distances is continuous with the smaller, longer-period first motion which precedes the $\overline{\mathrm{P}}$ beyond $50 \mathrm{~km}$. and was formerly designated as $P_{y}$.

Experimental attempts were made to apply the same method to the data of larger past shocks, such as the Long Beach earthquake of 1933. The smaller number of stations then available vitiates the method. The results using the epicenters and origin times derived by Gutenberg ${ }^{5}$ on the assumption that $\overline{\mathrm{P}}$ is the direct wave, led to a velocity near $5.5 \mathrm{~km} / \mathrm{sec}$; ; but it was then found that the attempt to determine depth led to an absurdity $\left(\Delta^{2}>D^{2}\right)$, so that the times recorded at the several stations apparently were not coherent.

The fact that 6 of the 8 shocks here used give velocities from 6.4 to 6.5 $\mathrm{km} / \mathrm{sec}$. is taken as evidence that at least the accidental errors of measurement and of choosing the origin time have been eliminated; the velocity found represents a true mean in the range of distances used. The epicenters are very well determined and not much affected by uncertainties of interpretation; hence the distances used in figure 1 are reliable, and the figure itself is a dependable foundation for a new standard travel time chart for southern California. The divergences among the calculated depths are probably largely illusory, since $h$ found in this way is very sensitive to slight changes in the origin time.

The small depth indicated for shock no. 8 suggests an explosion or road blast instead of an earthquake; however, the local Forest Service Office was unable to confirm this. Readings for No. 8 are not plotted in figure 1.

There are a few observations which probably refer to $P_{n}$. The travel time should be given by

$$
P_{n}-O=k+0.12405 \Delta
$$

The results are as follows:

\begin{tabular}{|c|c|c|c|c|c|c|}
\hline Shock no.......... & 3 & 4 & 3 & 4 & 3 & 4 \\
\hline Station............... & CL & $\mathrm{CL}$ & $\mathrm{H}$ & $\mathrm{H}$ & $\mathrm{T}$ & $\mathrm{T}$ \\
\hline$\Delta \ldots \ldots \ldots \ldots \ldots \ldots$ & 202.7 & 217.2 & 249.3 & 261.9 & 358.7 & 372.1 \\
\hline & 4.5 & 4.7 & 4.7 & 5.1 & 5.1 & 4.4 \\
\hline
\end{tabular}

4 Op. cit.

5 "Travel Times of Principal P and S Phases over Small Distances in Southern California," Bull. Seism. Soc. A m., 34: 13-32 (1944); "Reflected and Minor Phases in Records of Near-by Earthquakes in Southern California," ibid., pp. 137-159. 
The mean value of $k$ is thus 4.7. The corresponding value taken as typical by Gutenberg ${ }^{6}$ is 6.2 ; this indicates that the origin times of the shocks are 1.5 seconds earlier than those which would be found using the velocities and travel times determined in 1944. This is exactly the result now found by Gutenberg (1949).

The ratio of the velocity of $P$ to that of $S$ can be determined by dividing the travel time of the first $\mathrm{S}$ in table 1 by that of the first $\mathrm{P}$, for distances up to $75 \mathrm{~km}$. The mean of these quotients is 1.76 . For a $P$ velocity of 6.4 to 6.5 this implies an $\mathrm{S}$ velocity of about 3.6. The ratio of $\mathrm{P}-\mathrm{O}$ to $\mathrm{S}-\mathrm{P}$ would then be nearer 1.3 than 1.4.

Mr. J. M. Nordquist has drafted the figures and assisted with some of the calculations.

The writer is indebted to Dr. B. Gutenberg for much helpful discussion.

Note added in proof.-To improve the value taken for the mean velocity, $D$ was calculated from the values of $\Delta$ given in table 2 , assuming $h=16 \mathrm{~km}$; residuals in time of first motion were computed for $t=0.158 \mathrm{D}$, reducing the observed times at MW, Cr and Pr by 0.1 second. Shocks 1 to 7 showed individual systematic deviations for all stations. The assumed origin times were altered by the means of these deviations, which for the seven shocks were, in order $-0.37,+0.36,+0.11,+0.37,+0.32,-0.29,-0.26$ seconds. The plotted residuals then fit a straight line with wholly negligible deviations. The best fit is for $t=0.1578 D$, which corresponds to $v=6.337 \mathrm{~km} /$ sec.

California Institute of Technology

Diviston of Geological Sctences

Contribution No. 518.

${ }^{6}$ See the preceding footnote. 